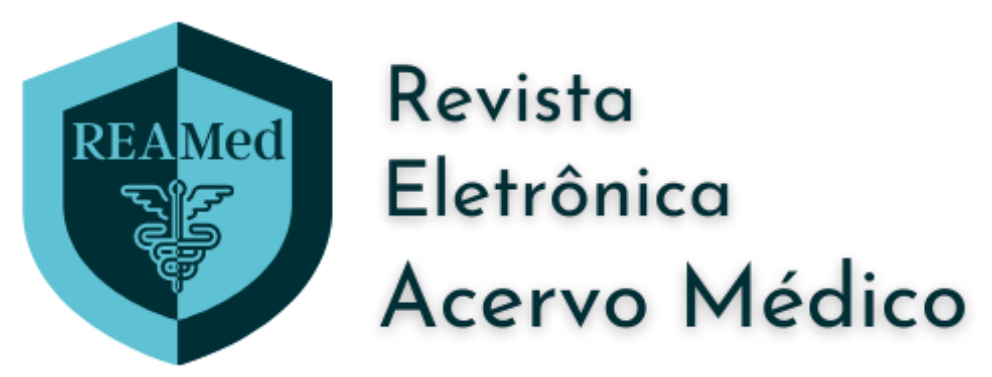

\title{
Fatores que predispõem a atividade do Lúpus Eritematoso Sistêmico
}

\author{
Factors that predispose to systemic Lupus Erythematosus Activity \\ Factores que predisponen a la actividad del Lupus Eritematoso Sistémico \\ Marjorie Rafaelly de Paula Venzo ${ }^{1 *}$, Najla Pinheiro Navarros ${ }^{1}$.
}

\begin{abstract}
RESUMO
Objetivo: Apresentar uma breve introdução sobre o Lúpus Eritematoso Sistêmico (LES) e discorrer sobre os fatores que predispõem a atividade da doença de forma atualizada. Revisão bibliográfica: O LES é uma doença autoimune de apresentação diversa, diagnosticada por uma combinação de sinais clínicos e laboratoriais. Entre os fatores predisponentes, os imunogenéticos são os mais conhecidos. Além dos fatores genéticos, as infecções virais, o estresse, a exposição ao sol e até mesmo a gravidez podem desencadear a ativação da doença. A população mais af etada é a de mulheres, sendo a causa hormonal a explicação mais aceita. O manejo da atividade consiste no uso de corticosteróides e anti-inflamatórios. Considerações finais: O Lúpus é uma doença autoimune, não dispondo de um tratamento curativo. Há uma relação constante da manifestação da doença com características genéticas e hormonais, sendo a sua atividade mais comumente ligada a inf ecções, exposições solares e uso de determinados medicamentos. São necessários novos estudos abordando os fatores predisponentes em populações maiores.
\end{abstract}

Palavras-chave: Lúpus eritematoso sistêmico, Doenças autoimunes, Fatores predisponentes.

\begin{abstract}
Objective: To present a brief introduction about Systemic Lupus Erythematosus (SLE) and discuss the factors that predispose the disease activity in an updated way. Bibliographic review: SLE is an autoimmune disease of diverse presentation, diagnosed by a combination of clinical and laboratory signs. Among the predisposing factors, immunogenetics are the best known. In addition to genetic factors, viral infections, stress, sun exposure and even pregnancy can trigger the activation of the disease. The most affected population is women, with hormonal causes being the most accepted explanation. Management of the activity consists of the use of corticosteroids and anti-inflammatory drugs. Final considerations: Lupus is an autoimmune disease, with no curative treatment. There is a constant relationship between the manifestation of the disease and genetic and hormonal characteristics, and its activity is most commonly linked to infections, sun ex posure and the use of certain medications. Further studies addressing predisposing factors in larger populations are needed.
\end{abstract}

Key words: Lupus erythematosus systemic, Autoimmune diseases, Causality.

1 Universidade de Cuiabá - Hospital Geral de Cuiabá, Cuiabá - MT. *E-mail: marjorievenzo@hotmail.com

SUBMETIDO EM: 1/2022

ACEITO EM: 1/2022

PUBLICADO EM: 1/2022 


\begin{abstract}
RESUMEN
Objetivo: Presentar una breve introducción sobre el Lupus Eritematoso Sistémico (LES) y discutir de forma actualizada los factores que predisponen a la actividad de la enfermedad. Revisión bibliográfica: EI LES es una enfermedad autoinmune de diversa presentación, diagnosticada por una combinación de signos clínicos y de laboratorio. Entre los factores predisponentes, la inmunogenética es la más conocida. Además de los factores genéticos, las infecciones virales, el estrés, la exposición solar e incluso el embarazo pueden desencadenar la activación de la enfermedad. La población más afectada son las mujeres, siendo las causas hormonales la explicación más aceptada. El manejo de la actividad consiste en el uso de corticoides y antiinflamatorios. Consideraciones finales: El lupus es una enfermedad autoinmune, sin tratamiento curativo. Existe una relación constante entre la manifestación de la enfermedad y las características genéticas y hormonales, y su actividad está más comúnmente ligada a infecciones, exposición solar y uso de ciertos medicamentos. Se necesitan más estudios que aborden los factores predisponentes en poblaciones más grandes.
\end{abstract}

Palabras clave: Lupus eritematoso sistémico, Enfermedades autoinmunes, Causalidad.

\title{
INTRODUÇÃO
}

O Lúpus Eritematoso Sistêmico (LES) é uma doença autoimune crônica que afeta vários órgãos, principalmente pele, articulações, sangue, rins e sistema nervoso central. A palavra "crônica" significa que pode durar muito tempo. A palavra "autoimune" significa que é um distúrbio d o sistema imunológico que ataca os próprios tecidos do paciente em vez de proteger o corpo contra bactérias e vírus (PARKS CG, et al., 2017).

O nome "lúpus eritematoso sistêmico" remonta ao início do século XX. A palavra "sistêmica" significa que a doença af eta muitos órgãos. A palavra "lúpus" é derivada da palavra latina para "lobo" e refere-se às típicas erupções faciais em forma de asa de borboleta da doença, que se assemelham às manchas brancas no rosto de um lobo. A palavra "eritematoso" é de origem grega e significa "vermelho"; refere-se à cor vermelha das erupções cutâneas (ANDRADE SO, et al., 2021).

A prevalência de lúpus (número de casos em uma determinada população em um momento específico) é difícil de avaliar. As estimativas variam entre 1 caso por 1.600 a 1 caso por 3.200 habitantes. O lúpus é encontrado principalmente em mulheres em idade fértil, ou seja, entre 15 e 45 anos. Também pode afetar homens (10 vezes menos que mulheres) e crianças. O lúpus está presente em todo o mundo, mas parece que certos grupos étnicos são mais af etados, como populações negras (e em particular índios ocidentais e afro-americanos) (OCAMPO-PIRAQUIVE V, et al., 2018).

Os fatores que causam e predispõem o lúpus tem sido amplamente estudados. Como se trata de uma doença autoimune, o tratamento consiste em controlar a atividade da doença e proporcionar melhor qualidade de vida para seus portadores, além de minimizar os ef eitos colaterais resultantes (FERNANDEZ D e KIROU $K A, 2016)$.

Partindo deste contexto, esta pesquisa buscou responder quais fatores predispõem a atividade da doença. Neste sentido, a presente busca teve como objetivo geral apresentar a doença lúpus e os fatores que a desencadeiam. Assim, os objetivos específicos buscaram descrever melhor a doença e seus sintomas, explanar quando ao tratamento e diagnóstico do Lúpus atualmente e porfim pontuar e apontar os fatores de predisposição da doença.

\section{REVISÃO BIBLIOGRÁFICA}

\section{A doença Lúpus}

O lúpus é reconhecido mundialmente. A doença parece ser mais comum em pessoas de ascendência afroamericana, hispânica, asiática ou nativa americana. Na Europa, cerca de 1 em 2.500 pessoas tem lúpus e cerca de $15 \%$ dos casos de lúpus são diagnosticados antes dos 18 anos (GERGIANAKI I, et al., 2018). 
O lúpus raramente aparece antes dos 5 anos de idade e é incomum antes da adolescência. Quando o LES aparece antes dos 18 anos, os médicos rotulam a doença como lúpus pediátrico, lúpus inf antil ou lúpus de início na infância. As mulheres em idade fértil (15-45 anos) são as mais af etadas e dentro deste grupo a proporção de mulheres af etadas para homens é de 9 para 1 (DURCAN L, et al., 2019).

O lúpus não é contagioso, é uma doença autoimune na qual o sistema imunológico não é mais capaz de distinguir substâncias estranhas das próprias células e tecidos de uma pessoa (DALL'ARA F, et al., 2018). O sistema imunológico se engana para produzir, entre outras substâncias, autoanticorpos que identificam as células normais de uma pessoa como estranhas e as atacam. Isso resulta em uma reação autoimune que, por sua vez, causa inflamação de certos órgãos específicos (articulações, rins, pele etc.) (FERNANDEZ D e KIROU KA, 2016). A palavra "inflamado" significa que as partes do corpo af etadas ficam vermelhas, quentes, inchadas e, às vezes, amolecem. Se os sinais de inflamação persistirem, como às vezes é o caso desta doença, os tecidos podem se deteriorar e apresentar mau funcionamento (ZUCCHI D, et al., 2019).

A doença pode se desenvolver lentamente no início, com novos sintomas aparecendo um após o outro ao longo de várias semanas ou meses, incluindo dor/inchaço nas articulações, erupção cutânea no rosto, fadiga. Muitas crianças com lúpus apresentam febre intermitente ou contínua, perda de peso e perda de apetite (PONS-ESTEL GJ, et al., 2017).

Ao longo do tempo, uma grande proporção de crianças desenvolve sintomas específicos devido a danos em um ou mais órgãos. A pele e as membranas mucosas são frequentemente afetadas e apresentam uma ampla gama de sintomas, como erupções cutâneas, fotossensibilidade (raios solares desencadeando erupções cutâneas) e úlceras nasais ou na boca. Erupções cutâneas típicas em forma de asa de bo rboleta no nariz e bochechas af etam entre um terço e metade das crianças af etadas (ANDRADE SO, et al., 2021).

Às vezes, a perda excessiva de cabelo (alopecia) é observada. As mãos ficam vermelhas, brancas e depois azuis quando expostas ao frio (fenômeno de Raynaud). Os sintomas também incluem inchaço e rigidez nas articulações, anemia, hematomas, dor de cabeça, convulsões e dores no peito. A maioria das crianças com lúpus sofre de lesão renal, o que é um importante fator determinante para o prognóstico da doença a longo prazo (MUNGUIA-REALPOZO $\mathrm{P}$, et al., 2019). Os sintomas mais comuns de lesão renal grave são pressão alta, proteína e sangue na urina e inchaço, especialmente dos pés, pernas e pálpebras (GERGIANAKI I, et al., 2018).

\section{Diagnóstico e tratamento do Lúpus}

O lúpus é diagnosticado por uma combinação de sinais clínicos e exames de sangue e urina, após descartar previamente outras doenças (CHOI MY, et al., 2017). Apenas certos sintomas ou sinais podem estar presentes em um determinado momento, dificultando o diagnóstico precoce do lúpus. Para distinguir o lúpus de outras doenças, foram compilados uma lista de 11 critérios que ajudam a classificar a doença (PARKS CG, et al., 2017).

Esses critérios correspondem aos sintomas/anormalidades observados com maior frequência em pacientes com lúpus. Para poder fazer o diagnóstico de lúpus, o paciente deve apresentar pelo menos 4 dessas 11 características em qualquer momento desde o início da doença (BARBHAIYA M e COSTENBADER $\mathrm{KH}, 2016)$. No entanto, médicos experientes podem diagnosticar a doença, e isso na presença de menos de 4 critérios (DOATY S, et al., 2016). Esses critérios são os seguintes (FERNANDEZ D e KIROU KA, 2016): Erupção na forma de asas de borboleta; Fotossensibilidade; Lúpus discoide; Úlceras da membrana mucosa; Artrite, Pleurisia ou pericardite; Lesão renal; Danos ao sistema nervoso central; Problemas no sangue, como hemólise e leucopenia; Doenças imunológicas; Presença de Anticorpo antinuclear (ANA).

Testes laboratoriais podem diagnosticar o lúpus e especificar quais órgãos internos podem ser af etados. Exames regulares de sangue e urina são importantes para monitorar a atividade e a gravidade da doença, bem como para determinar se os medicamentos são bem tolerados ou não (CHEN LY, et al., 2018). Existem vários exames laboratoriais que podem não apenas diagnosticar o lúpus e decidir quais medicamentos prescrever, mas também avaliar o ef eito dos medicamentos administrados na inflamação (ZUCCHI D, et al., 2019). 
Até o momento, não há medicamento específico para curar o lúpus. O tratamento ajuda a controlar os sinais e sintomas do lúpus e a prevenir complicações da doença, incluindo danos permanentes a órgãos e tecidos. Quando o lúpus é diagnosticado, geralmente é muito ativo (PONS-ESTEL GJ, et al., 2017). Nesse estágio, altas doses de medicamentos podem ser necessárias para controlar a doença e prevenir danos aos órgãos. Em muitas crianças, o tratamento regula os surtos de lúpus e a doença pode entrar em remissão, com tratamento reduzido ou inexistente ( $\mathrm{CHOI} \mathrm{MY,} \mathrm{et} \mathrm{al.,} \mathrm{2017).}$

Não existem medicamentos aprovados pelas autoridades de saúde para o tratamento do lúpus em crianças. A maioria dos sintomas do lúpus deve-se ao processo inflamatório; o tratamento, portanto, visa reverter esse processo inflamatório (DALL'ARA F, et al., 2018). Cinco grupos de medicamentos são usados em quase todo o mundo para tratar crianças com lúpus, são eles os Anti-inflamatórios Não Esteroides (AINEs), os antimaláricos, os corticosteroides, medicamentos modificadores da doença não biológicos e drogas biológicas modificadoras da doença (DOATY S, et al., 2016).

Anti-inflamatórios não esteroides, como ibuprofeno e naproxeno, são usados para aliviar a dor da artrite. Eles geralmente são prescritos porum curto período apenas com recomendações para diminuir à medida que a artrite diminui. Esta família inclui muitos medicamentos, incluindo aspirina (GUETTROT-IMBERT G, et al., 2016).

Atualmente, a aspirina é raramente utilizada por sua ação anti-inflamatória; no entanto, é amplamente utilizado em crianças com altos níveis de anticorpos antifosfolípides para prevenir coágulos sanguíneos (CHOI MY, et al., 2017).

Medicamentos antimaláricos, como hidroxicloroquina, são muito úteis no tratamento e controle de erupções cutâneas sensíveis ao sol, como erupções cutâneas que aparecem no lúpus discoide ou subagudo (MUNGUIA-REALPOZO P, et al., 2019). Os ef eitos benéficos dessas drogas só aparecem após vários meses. Se administrados cedo o suficiente, eles reduzem os surtos de doenças, melhoram o tratamento de danos nos rins e previnem doenças cardiovasculares. Lúpus e malária não estão relacionados (DURCAN L, et al., 2019). No entanto, a hidroxicloroquina ajuda a regular as anormalidades do sistema imunológico em pessoas com lúpus que geralmente af etam pessoas com malária (PARKS CG, et al., 2017).

Corticosteroides como prednisona ou prednisolona são usados para reduzir a inflamação e suprimir a atividade do sistema imunológico. Eles são o principal tratamento para o lúpus grave. Quando a doença é mais grave e os rins ou outros órgãos são afetados, eles são combinados com imunossupressores (BARBHAIYA M e COSTENBADER KH, 2016).

A dose inicial, bem como a frequência de administração, deste medicamento depende da gravidade da doença e dos órgãos af etados. Corticosteroides orais ou intravenosos em altas doses são geralmente usados para tratar anemia hemolítica grave, danos ao sistema nervoso central e danos renais mais graves. Se os corticosteroides forem administrados por um longo tempo e forem interrompidos repentinamente, o corpo pode não ser capaz de produzir cortisona suficiente por um tempo (ANDRADE SO, et al., 2021).

Medicamentos modificadores da doença não biológicos, incluem azatioprina, metotrexato, micofenolato de mofetil e ciclofosfamida. Seu modo de ação é diferente dos corticosteroides, pois suprimem a inflamação (OCAMPO-PIRAQUIVE V, et al., 2018).

Esses medicamentos são usados quando os corticoides isolados não controlam o lúpus; os médicos podem reduzir as doses diárias de corticosteroides para reduzir os ef eitos colaterais enquanto controlam os sintomas do lúpus. Micofenolato mofetil e azatioprina são administrados em comprimidos, enquanto a ciclofosfamida pode ser administrada em comprimidos ou injeções intravenosas (DURCAN L, et al., 2019).

$O$ tratamento à base de ciclofosfamida é para crianças com danos graves no sistema nervoso central ou nos rins. O metotrexato é administrado na forma de comprimidos ou injeções sob a pele (GERGIANAKI I, et al., 2018).

As drogas biológicas modificadoras da doença (ou simplesmente drogas biológicas) incluem agentes que inibem a produção de autoanticorpos ou o ef eito de uma molécula específica. Entre esses medicamentos está 
o rituximabe, que é usado principalmente quando o tratamento padrão falha. O belimumab é um produto biológico direcionado à produção de anticorpos de células $\mathrm{B}$ licenciado para tratar adultos com lúpus. De modo geral, o uso de agentes biológicos em crianças e adolescentes com lúpus ainda está em fase experimental (ANDRADE SO, et al., 2021).

A pesquisa no campo das doenças autoimunes, e especialmente do lúpus, é muito extensa. O objetivo é determinar os mecanismos específicos dos processos inflamatórios e autoimunes para melhor adequar os tratamentos sem suprimir o sistema imunológico em sua totalidade (GUETTROT-IMBERT G, et al., 2016). Atualmente, muitos estudos clínicos sobre lúpus estão em andamento. Eles visam testar novos medicamentos e ampliar o conhecimento dos diferentes aspectos do lúpus infantil. Graças a esses numerosos estudos, 0 futuro das crianças que sofrem de lúpus parece cada vez mais brilhante (DALL'ARA F, et al., 2018).

\section{Predisposição à doença}

A lúpus é uma doença autoimune, o que significa que as defesas imunológicas, que normalmente atacam apenas elementos "externos" (bactérias, vírus etc.), se voltam contra as próprias células do corpo e o atacam (FERNANDEZ D e KIROU KA, 2016). O corpo produz anticorpos nocivos (moléculas de defesa), chamados auto-anticorpos, que levam à autodestruição de certos tecidos (articulações, pele, rins etc.) e causam reações inflamatórias significativas. Ainda não se sabe porque as defesas imunológicas são interrompidas, mas vários fatores (ambientais, hormonais e genéticos) provavelmente estão envolvidos (ZUCCHI D, et al., 2019).

Entre os fatores predisponentes, os fatores imunogenéticos são os mais conhecidos: o risco de ter doença lúpica em dois gêmeos idênticos é 4 vezes maior do que em falsos gêmeos. O lúpus não está, de fato, associado a uma grande anomalia de um único gene (como na hemofilia), mas são diferentes particularidades genéticas que, quando associadas, predispõem ao desenvolvimento da doença ("doença multigênica") (DOATY S, et al., 2016).

Essas pequenas diferenças genéticas nos genes de imunidade são chamadas de "polimorfismos". Encontra-se, portanto, uma predisposição genética ao lúpus associada a determinados grupos HLA e a determinados genes, mas nenhuma anomalia, isoladamente, é suficiente para causar a doença (PONSESTEL GJ, et al., 2017). Os fatores ambientais que provavelmente participam do desencadeamento do lúpus são numerosos, mas, novamente, nenhum deles pode desencadear a doença sozinho. Certamente são necessários vários fatores ambientais (associados a vulnerabilidades genéticas do sistema imunológico) para causar a doença (CHOI MY, et al., 2017).

Os fatores ambientais mais conhecidos são os vírus, como os vírus da mononucleose infecciosa (vírus Epstein-Barr), e vários medicamentos (como procainamida, quinidina, hidralazina etc.), além de fatores tóxicos. Outros fatores mais conhecidos, como os raios ultravioleta (do sol) e os hormônios femininos (estrogênio), são sem dúvida mais importantes. Por outro lado, não há ocupação conhecida que favoreça o aparecimento do lúpus sistêmico (PARKS CG, et al., 2017).

Em alguns casos, uma infecção viral, estresse, exposição ao sol ou mesmo gravidez (por causa das alterações hormonais que provoca) podem desencadear o lúpus, ou melhor, "acordá-lo" por um mecanismo ainda desconhecido (BARBHAIYA M e COSTENBADER KH, 2016).

Certos medicamentos usados para tratar outras doenças (D-penicilamina, clorpromazina, certos anticonvulsivantes, betabloqueadores, minociclina) podem desencadear os sintomas do lúpus: isso é chamado de lúpus "induzido". Este lúpus pode desaparecer quando o tratamento é interrompido (ANDRADE SO, et al., 2021).

O lúpus, como a maioria das doenças autoimunes, af eta as mulheres com muito mais frequência do que os homens (9 mulheres para cada homem). Essa predominância feminina não é muito clara e provavelmente está relacionada a muitas causas, mesmo que possa ser explicada por diferenças hormonais ou genéticas (DALL'ARA F, et al., 2018).

A causa hormonal desta predominância feminina da doença é a explicação mais tradicionalmente avançada. Os hormônios femininos e, em particular, o estrogênio, em geral, promovem o excesso de 
imunidade observado no lúpus. Isso explica por que a doença pode piorar durante a gravidez, ao tomar contraceptivos hormonais à base de estrogênio ou durante a terapia de reposição hormonal após a menopausa (GERGIANAKI I, et al., 2018).

O cromossomo $X$, do qual as células femininas carregam duas cópias $(X X)$, enquanto as células masculinas carregam apenas uma (XY), é um cromossomo no qual encontram-se genes importantes do sistema imunológico. Foi demonstrado que uma mulher com lúpus expressaria os genes de imunidade transportados pelo cromossomo $X$ de forma diferente, o que poderia promover hiperatividade do sistema imunológico (GUETTROT-IMBERT G, et al., 2016).

Sabe-se que certos genes podem predispor à lúpus, ou seja, pessoas com esses genes são mais propensas do que outras a desenvolver lúpus (OCAMPO-PIRAQUIVE V, et al., 2018). Acontece que várias pessoas são af etadas pela doença dentro da mesma família (mas muito raramente dentro dos mesmos irmãos). No entanto, o lúpus não é transmitido diretamente de pais para filhos. Portanto, não é uma doença hereditária em si (CHEN LY, et al., 2018).

\section{CONSIDERAÇÕES FINAIS}

A doença do Lúpus, sendo uma doença autoimune, não tem cura. Porém, existem tratamentos para que a doença seja controlada o o indivíduo exerça sua vida normalmente. Há a constante relação da manif estação da doença com a genética, não no sentido hereditário, mas sim na mutação de genes. Também não o apontamento de qual gene exatamente desencadeia a doença, mas aponta-se existir algumas particularidades genéticas nos genes de imunidade. Além disso, aspectos como, ser do sexo feminino, ter tido infecção por alguns vírus específicos, grande exposição ao sol, situações de estresse e alguns medicamentos para tratar outras doenças, são fatores que predispõem a ativação da doença. Por fim, apontase a necessidade de realização de novos estudos que abordem o tema. Desta forma, sugere-se a aplicação de um estudo de caso, onde os fatores de predisposição possam ser melhor observados em uma população.

\section{REFERÊNCIAS}

1. ANDRADE SO, et al. Predicting lupus flares: epidemiological and disease related risk factors. Expert Rev Clin Immunol, 2021; 17(2):143-153.

2. BARBHAIYA $\mathrm{M}$, COSTENBADER $\mathrm{KH}$. Environmental exposures and the development of systemic lupus erythematosus. Curr Opin Rheumatol, 2016;28(5): 497-505.

3. CHEN LY, et al. Systemic lupus erythematosus with and without a family history: a meta-analysis. Lupus, 2018;27(5): 716-721.

4. CHOI MY, et al. A review on SLE and malignancy. Best Pract Res Clin Rheumatol, 2017;31(3):373-396.

5. DALL'ARA F, et al. Vitamin $D$ and systemic lupus erythematous: a review of immunological and clinical aspects. Clin Exp Rheumatol, 2018;36(1): 153-162.

6. DOATY S, et al. Infection and Lupus: Which Causes Which?. Curr Rheumatol Rep. 2016;18(3):13.

7. DURCAN L, et al. Management strategies and future directions for systemic lupus erythematosus in adults. Lancet, 2019;393(10188):2332-2343.

8. FERNANDEZ D, KIROU KA. What Causes Lupus Flares?. Curr Rheumatol Rep, 2016; 18(3): 14.

9. GERGIANAKI I, et al. Update on the epidemiology, risk factors, and disease outcomes of systemic lupus erythematosus. Best Pract Res Clin Rheumatol, 2018;32(2): 188-205.

10. GUETTROT-IMBERT G, et al. Pregnancy and contraception in systemic and cutaneous lupus erythematosus. Ann Dermatol Venereol, 2016;143(10):590-600.

11. MUNGUIA-REALPOZO P, et al. Systemic lupus erythematosus and hypertension. Autoimmun Rev, 2019; 18(10): 102371.

12. OCAMPO-PIRAQUIVE V, et al. Mortality in systemic lupus erythematosus: causes, predictors and interventions. Expert Rev Clin Immunol, 2018;14(12):1043-1053.

13. PARKS CG, et al. Understanding the role of environmental factors in the development of systemic lupus erythematosus. Best Pract Res Clin Rheumatol, 2017;31(3): 306-320.

14. PONS-ESTEL GJ, et al. Epidemiology of systemic lupus erythematosus. Expert Rev Clin Immunol , 2017; 13(8): 799814.

15. ZUCCHID, et al. One year in review 2019: systemic lupus erythematosus. Clin Exp Rheumatol, 2019;37(5):715-722. 